\title{
Award-Winning Faculty Online Teaching Practices: Roles and Competencies
}

\author{
Florence Martin, Kiran Budhrani \\ University of North Carolina Charlotte \\ Swapna Kumar, Albert Ritzhaupt \\ University of Florida
}

\begin{abstract}
The explosive growth of online learning in institutions of higher education has created a dire need for guidelines that instruct new and continuing online instructors about how best to teach in online spaces. The purpose of this exploratory study was to identify the roles of the online instructor and categorize critical competencies for online teaching based on a review of research and the perspectives of award-winning online faculty members. We interviewed eight award-winning online faculty members from across the United States. Based on interviews, it was found that online instructors assume five different roles: Facilitator, Course Designer, Content Manager, Subject Matter Expert, and Mentor. Common tasks of an online instructor course fell into two areas: Course Design or Teaching. This research has clear implications, not only for the literature research base, but for our institutions as well, as we continue to offer increasing numbers of effective online courses and programs to our students.
\end{abstract}

Keywords: competencies, online teaching, online instructor, instructor roles

Martin, F., Budhrani, K., Kumar, S., \& Ritzhaupt, A. (2019). Award-winning faculty online teaching practices: Roles and competencies. Online Learning, 23(1), 184-205. doi:10.24059/olj.v23i1.1329

\section{Award-Winning Faculty Online Teaching Practices: Roles and Competencies}

There has been a tremendous growth in online course delivery over the last decade. Allen and Seaman (2017) found that approximately 6 million students participated in at least one online course in higher education institutions in 2015, compared to 1.6 million in 2002. This growth has resulted in a need for more faculty members to teach online and has changed both the role of teachers and their teaching practices (Bennett \& Lockyer, 2004; Wiesenberg \& Stacey, 2008). While some traditional face-to-face classroom skills transfer adequately to the online environment, additional competencies are required for instructors to be successful in the online environment (Harasim, Hiltz, Teles, \& Turoff, 1997; Stephenson, 2001; Goodyear, 2002). Researchers have studied online learning and competencies required for online instructors (Smith, 2005; Darabi, Sikorski, \& Harvey, 2006; Bawane, \& Spector, 2009; Bigatel, Ragan, Kennan, May, \& Redmond, 2012). However, there exists a need for research to investigate the kind and level of expertise required among instructors to perform various roles in online teaching based on sound research methodologies. 
Ally (2008) defines online learning as "the use of the Internet to access learning materials; to interact with the content, instructor, and other learners; and to obtain support during the learning process, in order to acquire knowledge, to construct personal meaning, and to grow from the learning experience" (p. 5). Palloff and Pratt (2001) emphasize that in the online environment, the instructor plays the role of the facilitator and, in addition to the technology, needs to be given professional development and training to be a successful with online teaching. Allen and Seaman (2011) found that $6 \%$ of the 2,500 colleges and universities surveyed nationwide offering online courses reported having no training or mentoring programs for online teaching faculty. Issues in faculty training include: (1) little increase in the instructional and technical training and support needed by online faculty; (2) gaps in the quality of training received by online faculty; and (3) a constant push for more frequent and enhanced training to prepare confident faculty for the online environment Lackey (2011). This has resulted in a need to identify instructor competency areas in the online environment. This research adds to a growing body of knowledge about the roles and competencies of online instructors.

\section{Competency}

A competency is "a knowledge, skill or [ability] that enables one to effectively perform the activities of a given occupation or function to the standards expected in employment" (Richey, Fields \& Foxon, 2001, p. 26). Spector (2001, p. 2) refers to the term competence as "a state of being well qualified to perform an activity, task or job function" and competency refers to the "way that a state of competence can be demonstrated to the relevant community." Spector (2001) emphasizes that the constant changes in information and communication technology make it important for us to continually identify competencies for online teachers and provide them with professional preparation and training to be successful online instructors. Kerka (1998) states that competence "is individualized, emphasizes outcomes, and allows flexible pathways for achieving the outcomes - making as clear as possible what is to be achieved and the standards for measuring achievement" (p. 2). However, one of the challenges of using a competency-based approach is that a minimum level of performance is accepted rather than trying to aim for higher standards. Kerka recommends a holistic approach instead, where competence is seen "as a complex combination of knowledge, attitudes, skills, and values displayed in the context of task performance" (p. 6).

According to Thach and Murphy (1995), competency studies have been conducted primarily by interviewing a group of experts to gather their opinions on the skills and knowledge necessary to perform a job or function well. They further elaborate that in educational settings, it is recommended to use a method where competencies are linked to roles and outputs. Bawane (1999) used the ordinates shown in Figure 1 to identify competencies based on teacher roles.

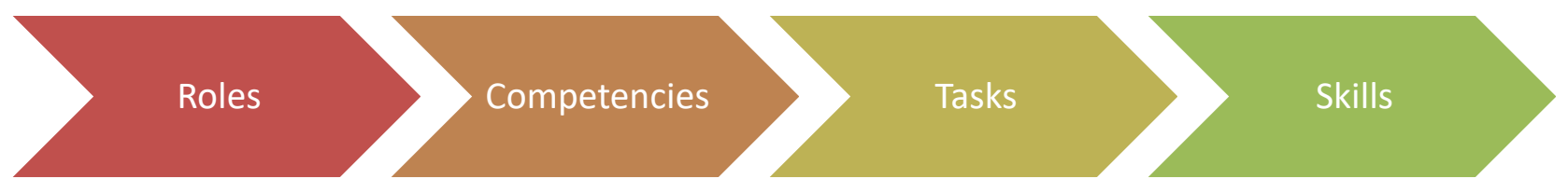

Figure 1. Competencies based on instructor roles. Adapted from Bawane, J., \& Spector, J.M. (2009). Prioritization of online instructor roles: implications for competency-based teacher education programs. Distance Education, 30, 385. 
In their research, Alvarez, Guasch and Espaso (2009) proposed the need to clarify both teacher roles and associated specific competencies and also the tasks that university instructors need to fulfill in online learning environments. Figure 2 shows the visual they used to depict the theoretical structure to define university instructor roles and competencies in online learning environments. Notably, both Bawane (1999) and Alvarez, Guasch and Espaso (2009) emphasize that roles be clearly outlined to identify the competencies.

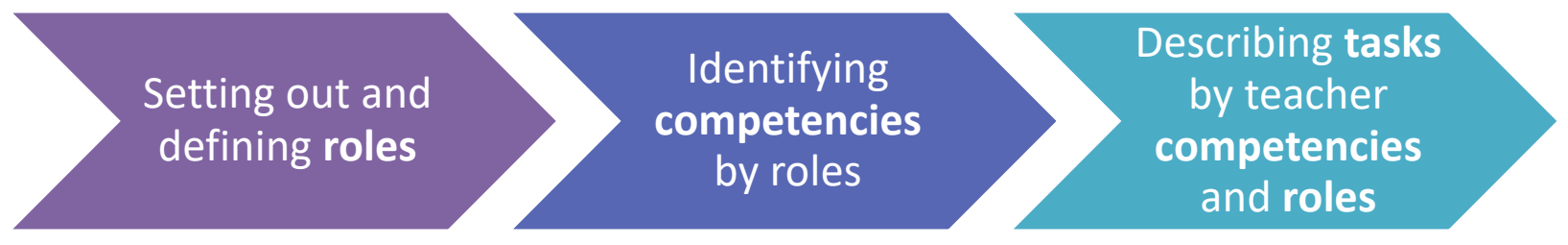

Figure 2. Roles, competencies, and tasks for instructors. Adapted from Alvarez, I., Guashch, T., \& Espasa, A. (2009). University teacher roles and competencies in online learning environments: A theoretical analysis of teaching and learning practices. European Journal of Teacher Education, $32,323$.

Darabi et al. (2006) drafted 20 online learning competencies from a review of the literature. Then, a total of 18 experts ( 5 from academia, 3 from industry, and 10 from the military) were selected and invited to participate in this validation process. The validation of the competencies resulted in 54 performance statements. Exactly 17 tasks were reported by $90 \%$ of the faculty members as commonly performed tasks in distance education. Bigatel, Ragan, Kennan, May and Redmond (2012) examined teaching behaviors, attitudes, and beliefs that reflect potential competencies for online teaching success. They constructed and distributed a survey instrument to experienced online faculty and staff members and asked them to rate the level of importance of a list of teaching tasks. Based on faculty interviews and a review of relevant research, researchers identified 64 teaching tasks. Smith (2005) identified 51 competencies for online instructors, noting whether the competency was of primary importance before, during, and/or after the course.

\section{Roles of Online Instructor}

The online instructor's role is very important to the success of online learning. The advent of online learning, lecture-based classes online, and the transformation of the instructor role requires a paradigm shift. Through the use of discourse analysis, Beck and Ferdig (2008) revealed that the role of the teacher transformed from teacher-centered to student-centered, low-interaction to high-interaction, and low-initiator to high-initiator. Easton (2003) found that online instructor roles require a paradigm shift regarding instructional time and space, virtual management techniques, and the ability to engage students through virtual communication. Several researchers have identified various roles for online instructors as outlined in Table 1. 
Table 1.

Roles of Online Instructors

\section{Online instructor roles}

Instructor, instructional designer, technology expert, technician, administrator, site facilitator, editor, librarian, evaluation specialist, graphic designer

Process facilitator, advisor/counselor, assessor, researcher, content facilitator, technologist, designer, and manager/administrator

Cognitive, affective, and managerial

Administrative manager, instructor/facilitator, instructional designer, trainer, leader/change agent, technology expert, graphic designer, media publisher/editor, technician, support staff, librarian, evaluation specialist, site facilitator/proctor

Pedagogical, communicational, discipline expertise, and technological

Administrative, design, facilitation, evaluation, and technical based on instructional theory, research and experience

Content expert, process facilitator, instructional designer, advisor/counselor, technologist, assessor, material producer, administrator

Administrative, personal, technological, instructional design, pedagogical, assessment, social roles

Professional, pedagogical, social, evaluator, administrator, technologist, advisor/counselor, and researcher

Pedagogical, social, managerial, technical

Design/planning, social, cognitive, technological, management

Preparation, planning, design, facilitation, interaction, providing/gathering feedback, reflection

Active learning, Active teaching/responsiveness, administration/leadership, classroom decorum, policy enforcement, multimedia technology, technical competence

Leadership \& instruction, active teaching, community \& netiquette, tools \& technology, instructional design

\section{Researchers}

Thach and Murphy (1995)

Goodyear, Salmon, Spector, Steeples \& Tickner (2001)

Coppola, Hiltz, \& Rotter, (2002)

Williams (2003)

Dennis, Watland, Pirotte, and Verday (2004)

Shank (2004)

Aydin (2005)

Varvel (2007)

Bawane \& Spector (2009)

Berge (2009)

Alvarez, Guasch and Espaso (2009)

Abdous (2011)

Bigatel, Ragan, Kennan, May, and Redmond (2012)

Farmer \& Ramsdale (2016) 


\section{Purpose of the Study and Research Questions}

While we have several research studies that highlight best practices for online instructors (e.g. DiPietro, Ferdig, Black, \& Preston, 2008; Keengwe \& Kidd, 2010), the literature base still does not provide clear guidelines on the evolving necessary roles and competencies of effective online instructors. Enumerating these competencies can provide instructional designers, faculty members, directors of online education, and other relevant stakeholders with clear guidelines about how best to prepare future online instructors to teach in dynamic online spaces. The purpose of this exploratory study was to identify the roles of the online instructor and categorize the critical competencies for online teaching based on a review of research and the perspectives of experienced, award-winning online instructors based on interviews. The key research questions that guided this research are:

1. What are award-winning online faculty perspectives regarding the various roles for online instructors?

2. What are award-winning online faculty perspectives regarding the key competencies for online teaching?

\section{Methods}

In this section, we outline the participants, procedures, interview instrument, and data collection and analysis of this exploratory research study.

\section{Participants}

Eight of the fifteen faculty members who had won awards for online teaching were contacted by email and agreed to participate in the online interview. The interview participants included eight distinguished online instructors who have either won the Excellence in Online Teaching Award from the Online Learning Consortium or the Crystal Online Teaching Award from Association for Educational Communications and Technology, two large professional organizations dedicated to the research and practice of online learning and teaching. Six of the interviewees were female and two were male. Participants had experience teaching in both asynchronous and synchronous learning spaces using a variety of platforms including Desire2Learn, Blackboard, WebCT, Canvas, and Moodle.

Table 2.

Demographics of Eight Award-winning Faculty Members

\begin{tabular}{|c|c|c|c|c|c|c|}
\hline ID & Gender & Award & $\begin{array}{l}\text { Years } \\
\text { Teaching } \\
\text { in H.E. }\end{array}$ & $\begin{array}{l}\text { Years } \\
\text { Teaching } \\
\text { Online }\end{array}$ & $\begin{array}{l}\text { LMS } \\
\text { Experience }\end{array}$ & Modality \\
\hline 1 & $\mathrm{~F}$ & $\begin{array}{l}\text { Excellence in Online } \\
\text { Teaching, OLC Award }\end{array}$ & 20 & 15 & $\begin{array}{l}\text { Genzibar, } \\
\text { WebCT, } \\
\text { Desire2Learn, } \\
\text { Canvas, } \\
\text { Blackboard }\end{array}$ & $\begin{array}{l}\text { Blend of } \\
\text { Asynchronous } \\
\text { and Synchronous }\end{array}$ \\
\hline 2 & $\mathrm{~F}$ & $\begin{array}{l}\text { Excellence in Online } \\
\text { Teaching, OLC Award }\end{array}$ & 30 & 6 & Blackboard & Asynchronous \\
\hline 3 & $\mathrm{~F}$ & $\begin{array}{l}\text { Excellence in Online } \\
\text { Teaching, OLC Award }\end{array}$ & 14 & 12 & $\begin{array}{l}\text { Blackboard, } \\
\text { Moodle, } \\
\text { Canvas }\end{array}$ & Asynchronous \\
\hline
\end{tabular}




\begin{tabular}{|c|c|c|c|c|c|c|}
\hline 4 & $\mathrm{~F}$ & Crystal Award, AECT & 23 & 5 & $\begin{array}{l}\text { WebCT, } \\
\text { Blackboard, } \\
\text { WordPress, } \\
\text { WikiSpaces }\end{array}$ & $\begin{array}{l}\text { Mostly } \\
\text { Asynchronous } \\
\text { with some } \\
\text { Synchronous }\end{array}$ \\
\hline 5 & $\mathrm{~F}$ & Crystal Award, AECT & 15 & 5 & $\begin{array}{l}\text { None } \\
\text { identified }\end{array}$ & $\begin{array}{l}\text { Blend of } \\
\text { Asynchronous } \\
\text { and Synchronous }\end{array}$ \\
\hline 6 & M & $\begin{array}{l}\text { Gold, Online Technology } \\
\text { Higher Education, Best } \\
\text { Practices Awards for } \\
\text { Excellence in Distance } \\
\text { Learning Teaching }\end{array}$ & 31 & 9 & Blackboard & $\begin{array}{l}\text { Mostly } \\
\text { Asynchronous } \\
\text { with some } \\
\text { Synchronous }\end{array}$ \\
\hline 7 & M & $\begin{array}{l}\text { Excellence in Online } \\
\text { Teaching, OLC Award }\end{array}$ & 44 & 42 & Blackboard & Asynchronous \\
\hline 8 & $\mathrm{~F}$ & $\begin{array}{l}\text { Excellence in Online } \\
\text { Teaching, OLC Award }\end{array}$ & 18 & 15 & $\begin{array}{l}\text { CAD, } \\
\text { Blackboard, } \\
\text { Interlearn, } \\
\text { Moodle }\end{array}$ & Asynchronous \\
\hline
\end{tabular}

\section{Procedures}

The research project was executed in three distinct phases: 1) review of existing research literature on online faculty roles and competencies, 2) development of interview guide based on the literature to interview award-winning online instructors, 3) interview award-winning faculty members teaching online at various institutions of higher education within the United States. We interviewed the eight faculty members via Goto Meeting to learn about what they do in their online courses. To aid in the data collection process, we presented the interview questions on a shared screen to assist the interviewee in answering our questions. All interviews were digitally recorded for later transcription and coding.

\section{Instrument}

As noted, we reviewed the existing literature as a starting place to identify roles and competencies for online instructors. Using the online instructor roles and competencies in the literature as a guide, we then developed a semi-structured interview protocol with 14 questions to collect in-depth qualitative information from award-winning online instructors. For example, one question read "What are the various roles instructors take on in online learning?" All questions were carefully reviewed by members of the research team, all of whom have taught online, for clarity and intent.

\section{Data Collection and Analysis}

The interviews were recorded, transcribed, and analyzed using the constant comparative method. The constant comparative qualitative procedure was selected because it "is concerned with generating and plausibly suggesting (but not provisionally testing) many categories, properties, and hypotheses about general problems" (Glaser \& Strauss, 1967, p. 104). Two researchers first read through each interview to ensure that the same questions had been asked and made notes pertaining to additional responses. The data were then compiled by responses to research questions across the eight interviews in order to compare the experiences and responses of all interviewees. Each set of responses then underwent open coding and axial coding (Strauss \& Corbin, 1990, p. 96). Both researchers open coded all eight responses to one question and met to discuss their codes. They then coded the data for the remaining questions. The codes were reviewed by both researchers to reach agreement. The codebook was then examined to eliminate redundancy and grouped together pertinent codes into categories. The resulting categories were then compared across questions to consolidate and finalize the themes. 


\section{Results}

\section{Roles and Responsibilities of Online Instructors}

Participants stated that, at various times, online instructors take on several roles, such as course designer, teacher, mentor, facilitator, "cheerleader," and even a "rule-setter." They viewed an important component of online pedagogy as "the engagement, the support, the mentoring of the students as they move through courses." The online instructor roles described in the interviews were facilitator, course designer, course manager, subject matter expert, and mentor.

Facilitator. The most important role of the online instructor, according to those interviewed, is that of the facilitator and instructor "presence." They stated that "being there" for students and "having a presence that the students felt on the course site" were essential. Participants explained what "presence" meant to them in the following examples:

- Create a video to introduce themselves at the beginning of a course

- Include "early activities" to make students comfortable with the technology

- Check in with students regularly

- Engage with students to make the course interactive

- Get in touch with students to motivate them to complete the course

- Help students manage their time and be successful

- Help students develop self-regulated learning skills

- Establish a "personal connection"

- Hold online office hours

- Be responsive to individual students and the group throughout the course, but being available as much as possible just before assignments were due

- Use other means of synchronous and asynchronous communication when required, e.g. texting

- Resolve student problems and questions as quickly as possible

- Be present in discussion forums

- "Letting students know you are reading"

- Use formative assessment in the form of quizzes, discussion posts, online meets or synchronous sessions, short papers, projects, etc.

- Provide "timely, actionable, and substantive" feedback on assignments

One participant summarized by saying, "So the most important role for the instructor is to be present, to be available, to be a facilitator, and to be able to share his/her expertise online and to model for the students what it really means to participate in an online course."

Three participants also named student engagement in their role as an online instructor. They believed "if you don't engage your students, they are not going to learn," and that online instructors have to engage students and "focus on interactivity within their teaching where they can foster student to student interaction as well as instructor to student interaction." Examples of engagement given by the participants were authentic projects and interactive experiences. One participant described an interactive experience as one where different media are used, giving an example from her class: "Sometimes I record myself like this for a lecture or link them to videos. I teach poetry class online and I am able to link them directly to poets and their works, there are resources there." Another participant stated, "I think we have an ethical responsibility to make the course interesting." They emphasized student engagement by asserting that it is "an incredibly important role that educators should embrace" and "essential for the online instructor to be highly engaged online." 
Similar to the face-to-face classroom, online instructors have to assess student learning. According to participants, formative assessment and the choice of technologies or assignments play a key role in online course design. Online instructors have to reflect on "how well the tools you've selected work for a particular learning assignment that you've set up...how your own course design is benefitting the student learning process or not."

Course designer. Course design was mentioned by all eight participants as an integral part of their role as online instructors. They elaborated on various areas of course design such as establishing learning objectives, including active learning strategies, visualizing a course design that is compatible with the content and course delivery approach, and ensuring it is accessible and ADA-compliant. Several participants mentioned course shell development as part of course design. One participant believed the course design should get "the students excited about developing progressive mastery with the material," while another reflected, "You also take on the role of designer in a very different kind of way than you do in a classroom...we could really be designing the classroom, the piece of designing - if you will, the chassis - the course goes in, at least where we did not have any instructional design support." Another participant also stated that adopting a design-based approach by reviewing what worked or not and revising it for the next offering was an essential part of course design by an online instructor.

The role of the instructor as course designer, however, depends on the type of institution in which an online instructor works, the structure within the institution, and the availability of support within the institution, according to the participants. For example, those who have no support available build and teach their course on their own, whereas one participant works within a "centralized and outcome-based curriculum model," where the course is built over a few months using a team with "diverse expertise including instructional designers, learning scientists, editors, multimedia specialists, subject matter faculty, student learning center representatives, librarians, and instructional technologists." The course is completely developed by the team of collaborators and the instructor "receives that course two weeks prior to the start date of the course." Two participants also emphasized that it is "not the job of the instructor to provide technical support," although they should be able to point students to resources for help and support. They asserted that all universities offering online courses should have technical instructions and resources within the Learning Management System for students, for example, in areas such as "how to upload files," "how to submit assignments," and "how to use collaborative learning spaces, whether synchronous or asynchronous."

Course Manager. Three participants mentioned course management as the main responsibility of the online instructor. As one explained:

...that's just my term for any of the nuts and bolts. Things such as providing content in whatever form, if it is a video or an online lecture, text on a page, and then also grading, collecting assignments, encouraging students who are not attending, all that sorts of behind the scenes. Here at my institution, we do attendance. If a student doesn't check in in some way, once a week, then they are counted as absent. That is kind of an interesting thing I had to get used to here. That's what I call course delivery. 
Subject Matter Expert. Four of the eight faculty interviewed viewed the role of the online instructor primarily as a content expert or subject matter expert. They found it important to demonstrate their content expertise in the instructional design, choice of content, and connection of content to current events or practice. One participant stated that this role requires the instructor to stay abreast of research, techniques, and theories behind why certain practices are useful.

Mentor. Three participants also viewed themselves as a mentor or a coach who not only taught a course but also advised students about their academic and professional development. One participant described him/herself as "the person who tries to instill what the profession is about" because the courses she teaches are more professionally oriented. Another participant described this as some of the hats that the instructors wear and elaborated,

I end up having conferences with students involving their writing. I also find myself mentor to some students, online students, really speaking to them about career goals and career paths as adviser. It seems to be the case that my online students really seek me out in this regard, I don't know exactly why. But they often times look for advice in terms of both course offerings and just strategies within the online program. And also advise post- graduation and also career advice. I actually spend a fair amount of time with a lot of my students talking about tons of issues really apart from the course.

Similar to their responses about the online instructor role, participants believed that their main responsibility was to create an effective and productive learning experience for the students. They did this by engaging students, ensuring student interaction, being responsive in all communication areas of a course, and providing detailed instructions and expectations. One participant stated that instructors have to be "more intentional online" in order to facilitate learning for all types of learners. Another elaborated:

My main responsibility is to be able to leverage the affordances of the technologies that I'm using to really engage the students to make the course meaningful, to make it engaging, to make it as interactive as possible. To make sure that there are meaningful learner interactions, learner-instructor interactions, you know learnergroup interactions, learner-content interactions, to be able to make all these interactions happen in a meaningful way in a way that they support the learning outcomes for the course.

Another key responsibility, particularly in fully asynchronous courses, is to have a presence that the students feel. One participant expressed that there needs to be some "kind of a personal connection" where it is the responsibility of the instructor to connect back to bridge the disembodiment potential in online education. 
Table 3.

Roles and Responsibilities of Online Instructors

(1) Facilitator

- Create a welcome video

- Include "early activities" to make students comfortable with the technology

- Check in with students regularly

- Get in touch with students to motivate them to complete the course

- Help students manage time

- Help students develop self-regulated learning skills

- Hold online office hours

- Be quick and responsive to individual students needs

- Communicate in synchronous and asynchronous modes when required, e.g. texting

- Be present in discussion forums

- Use formative assessment in the form of quizzes, discussion posts, online meetings or synchronous sessions, short papers, projects, etc.

- Provide timely, actionable, and substantive feedback

- Be present and available

- Model for students what it means to participate online

- Foster student engagement, interest, and interaction (e.g., authentic projects, interactive experiences)

- Use media to enhance student interest

(2) Course Designer $\quad$ Establish learning objectives

- Use active learning strategies to promote excitement and engagement

- Align course design to content and delivery approach

- Ensure accessibility and ADA-compliance

- Develop a course shell

- Adopt a design-based approach to improve courses

- Point students to resources for help and support

(3) Course Manager - Provide content (e.g., video, online lecture, text on a page)

- Grade and collect assignments

- Encourage students who are not attending

- Assess student learning (e.g., formative assessment)

- Reflect on course design

(4) Subject Matter Expert • Demonstrate content expertise

- Stay abreast with research, techniques, and theories behind why certain techniques are useful

(5) Mentor

- Advise students on their academic and professional development.

- Instill what the profession is about

- Be professionally oriented

- Have conferences with students

- Advise on career goals and career paths

- Advice on course offerings 


\section{Tasks Performed by Online Instructors}

When asked to describe their common tasks, participants' responses fell into two areas: course design or teaching.

Course design. Tasks commonly performed by online instructors in the area of course design were structuring and organizing an online course, finding and selecting content, making decisions about what content to include and exclude, creating course activities, chunking the content appropriately, developing materials and activities, designing assessments, and developing syllabi. Reviewing the previous offering of a course to make revisions to the planned offering was also a task mentioned by some participants.

Teaching. Common tasks performed by online instructors at the beginning of an online course were to welcome students, get to know them, and to get to know their challenges. A welcome video and/or discussion forum were common strategies used by the participants. One participant sends out a survey during the first week of class that requests students' preferred contact information and asks basic demographic questions. The participant explained his strategy:

I think the two most telling questions are described in one word- "how are you feeling about this course?" And with that one question, I get responses that are usually in the neutral or positive category but sometimes I'll have students usually in every class that says nervous or anxious and that allows for me to reach out for them so the effort to be aware of their needs and make that connection early on, support that kind of social emotional connection and then the last question that I ask is, "Is there anything I need to know about you in this class?" that allows me to identify the first week the students who have shared with me that they're pregnant and they're gonna give birth halfway thru the term. I had a student who had epilepsy who had concerns about speaking because she had you know slurred speech. Those kinds of concerns that normal students wouldn't say, "hey, this is what's going on with me!" for me to be aware and ask those questions does really help me to come in and provide that emotional support which is really important.

Interacting with students, facilitating discussions, and actively making efforts to identify what's going on were other teaching tasks that participants mentioned. One participant makes it a practice to summarize online discussions after students have completed them. He elaborated as follows:

[I would] facilitate the discussion, if it's a blog I would comment on their blogs, I would also have them provide peer comments in their blogs, I would synthesize the blogs in the end to try to tell them what knowledge it has generated for the class. I would be the facilitator of those learning activities, the aggregator, and the synthesizer after you know I've designed it.

Participants routinely provided direct feedback, tried to be empathetic, and always tried to be visible, often using audio or video to communicate with students or provide feedback. One participant shared:

So being actively present and engaged and be visible. By visible I mean through voice and/or video so that students have a sense of you know: they can hear the intonation in your voice, they can see you. Let the student know that you've heard or understand them. And so that's something that I've had a lot of success doing that with the tool that I use called VoiceThread because it allows for me to be present in voice and I can provide direct feedback to students. 


\section{Competencies of Online Instructors}

Participants were asked two questions about the competencies needed by online instructors: a general question about the competencies needed by online instructors to fulfill the roles they had mentioned, and a question about the technical competencies needed by online instructors. The technical competencies brought up by participants are first presented in this section, followed by the general competencies: willingness to learn, knowledge of how people learn, content expertise, course design skills, and student learning assessment skills.

Technical skills. Participants listed the ability to use the learning management system (LMS) to design and teach the course, and other technology skills (E-mail, navigate browser windows, file upload and download, and PDF creation) as both basic and essential for online teaching. The development of audio and video materials was a skill declared by all participants to be important.

Online instructors should be able to create videos and Screencasts quickly and on their own, if necessary, in order to model for students "what it means to actively participate in the use of technologies." Further, knowing how to record others and themselves with a microphone, how to record voice with PowerPoint, how to use free tools for Screencasting, and how to use a webcam with the LMS were perceived as critical. One participant highlighted the connection between online instructors' comfort level with technology to teaching strategies needed in the online environment such as creating or uploading videos, providing online feedback, and using collaborative technologies. Another participant emphasized the importance of not only technical skills, but the affordance of the technologies that could be used in an online course. Such knowledge, according to a third participant, could help online instructors access and use technologies to create additional materials if students had difficulties in a course.

Finally, technical writing was mentioned by one participant as crucial for the creation of video and audio materials, which require different means of communication with students than in person. He stated, "They should be able to write for the web and writing for the web is not the same as writing a paper for an academic conference. They should be able to write or look at things from a visual perspective, in terms of graphic design and make things."

The willingness to learn. The competency most often mentioned across the eight interviews was online instructors' willingness to learn and grow, with respect to both pedagogy and technology skills. Making the move to teaching online from teaching on-campus, according to the instructors interviewed, necessitated "being able to see oneself as an online learner," who grows constantly. They stated that instructors need to take the time to learn about online learning and teaching. One participant stated, "That willingness to go from a role of subject-matter expert which often times is really that the way they've seen themselves, is kind of the crux of their capacity as a faculty member in a classroom and in an online classroom. To do it effectively it requires so much more than that." Another asserted that the desire to teach well was crucial: "You need to have the desire to help facilitate students to learn and be very, very engaged and dedicated to those students and the mission." Online instructors' willingness to allot time to learning to teach online has to also be accompanied by the understanding that "if they want to be successful in an online teaching space they need allocate more time than they are used to in a traditional course," according to one participant, "because interacting with students in an online medium requires a lot of time and presence."

The willingness to learn how to use technology and to experiment with technologies was considered an important competency by several of those interviewed. This helps instructors "synthesize and analyze which piece of technology is going to work and which is not," when 
teaching online. The willingness to learn can also help faculty feel comfortable with technologies needed to teach online and assist students if they have technical problems. For participants, the willingness to learn and try new technologies reflect "risk-taking and a growth mindset," "a willingness to make mistakes and learn from those mistakes instead of feeling shameful that they did something wrong," and the "willingness to be exposed to new things."

Three participants stated that in addition to new technologies, instructors should keep up with the latest research about online teaching. It is important for them to "stay abreast with research, to stay up with different techniques, not just the bells and whistles of a class, but some of the theories and research behind why things are useful." In order to do so, instructors should participate in training in these areas.

Knowledge of "how people learn." A key competency, according to participants, is an understanding of how people learn and how students learn online. They gave various examples of what it means to understand how people learn. One participant explained,

You don't need to be a learning scientist, but you need to understand how people learn. For instance, some people may learn better with synchronous sessions, they need the immediacy of the feedback and that really increases their capability to add on to that pyramid of learning. As they pull in new skills, they kind of categorize that in their minds, so you need to have both. You need to have the content expertise, but you need to have an understanding on the way that the students learn.

Another participant stated that understanding how students learn and how to teach online students is needed to engage them in the course. A third participant explained that he believed in learning styles and developed and evaluated courses once they finished according to those styles. For example, he uses podcasts to convey his expertise, especially for those students whose preferred style of learning is auditory. He includes projects so that students complete an activity. He is also very cognizant of "social versus solitary" learning styles, so he designs his courses to include activities that address both these styles. He said,

what I do is mix it up so that they will have a chance to be social and solitary if they want to. So, when they submit their essays to me as a solitary activity, the social activities would be a poster story online and I have students who resist that at first. It's one of the requirements for the course, you have to post in the class email list, and they have to look at it and critique it and talk with each other.

Content expertise. Participants believed that being an expert in the field-knowing the content or subject matter-is important, but that online instructors additionally needed to understand how to "deliver the content appropriately" through the online medium and to facilitate learning. One participant explained, "That competency would involve understand[ing] the content and then being able to deliver it and translating that knowledge into teaching. Just because we teach, doesn't mean they are going to learn."

Course design skills. Instructional design skills are an essential competency for online instructors, according to the participants, even if they have access to instructional designers at their institution. Knowledge of backwards course design and web accessibility regulations are needed not only to design, but also to facilitate a course. Specific design areas mentioned by participants were the ability to

- write learning objectives

- chunk content into manageable parts 
- develop lessons in a logical sequence

- assess students formatively to ensure progress

They also highlighted that online instructors have to understand and be competent to create community among online students or build social presence. This included creating an "online environment that is safe, that is something that students feel comfortable participating in." One participant had a golden rule for netiquette, set up "very early on" in an introductory session in a course. These rules included what could be said or not said on discussion boards and when communicating with the instructor and peers.

Assess student learning. The ability to design assessments and provide feedback that helps students progress was identified as an online instructor competency by the participants. While several participants emphasized the provision of feedback, two pointed out the importance of assessment design, as evidenced in this comment,

...how do you set up a learning objective and design an assignment and know at the end of that assignment that the student met that learning objective; so there's a design element to creating the content and learning experience for the student and when I say assessment the faculty members needs to be able to do two things, one is assess student learning and two assess their own assignment to know if they've gotten students to go where they wanted it to.

Participants highlighted the provision of timely, consistent individual and group feedback, and the ability and understanding that student data can provide information about student progress as essential for online instructors. Taking the time to give meaningful feedback and provide it in various ways was also considered important in the online environment. One participant explained:

They get short audio files in which I'm talking to them and as well having them read the written comments I've given them. So, I think that faculty need to know the tools to help them reach the students. We have students now, who expect that they use these things all the time, and they expect more from us.

Table 4.

Competencies of Online Instructors

(1) Technical Skills - Use a learning management system (LMS) to design and deliver courses

- E-mail

- Navigate browser windows

- Upload and download files

- Create PDFs

- Develop of audio/video materials (e.g., screencasts, videos)

- Record others and themselves with a microphone

- Record voice narration with PowerPoint

- Use free tools

- Use a webcam

- Provide online feedback

- Use collaborative technologies

- Create additional materials for students experiencing difficulties

- Write for media and the web to communicate in video and audio formats (i.e. Technical writing)

- Communicate with a visual perspective 


\begin{tabular}{|c|c|}
\hline $\begin{array}{l}\text { (2) Willingness } \\
\text { to learn }\end{array}$ & $\begin{array}{l}\text { - Grow in pedagogy and technology skills } \\
\text { - } \text { Make the move to teaching online from teaching face-to-face } \\
\text { - See oneself as a learner } \\
\text { - } \text { Embrace oneself as a life-long learner } \\
\text { - Have the desire to teach well, to help facilitate student learning, to be } \\
\text { very engaged, and to be dedicated to students and the mission of the } \\
\text { - } \text { - Expeol } \\
\text { - Willingness to make mistakes and learn from mistakes } \\
\text { - Be exposed to new things } \\
\text { - Stay abreast with the latest research, theories, techniques on teaching } \\
\text { - } \text { Participate in training }\end{array}$ \\
\hline $\begin{array}{l}\text { (3) Knowledge of } \\
\text { "how people learn", }\end{array}$ & $\begin{array}{l}\text { - Understand how students learn in synchronous and asynchronous modes } \\
\text { - Develop a mix of activities for various learning styles (e.g., social vs. } \\
\text { solitary, oral vs. visual) } \\
\text { - Evaluate courses according to learning style }\end{array}$ \\
\hline $\begin{array}{l}\text { (4) Content } \\
\text { Expertise }\end{array}$ & $\begin{array}{l}\text { - Be an expert in the field } \\
\text { - Know the content or subject matter } \\
\text { - Understand content to be able to deliver it effectively for learners } \\
\text { - Translate content knowledge into "teaching" }\end{array}$ \\
\hline (5) Course Design & $\begin{array}{l}\text { - } \text { Instructional design skills } \\
\text { - Knowledge of backwards course design } \\
\text { - Knowledge of web accessibility regulations } \\
\text { - } \text { Write learning objectives } \\
\text { - } \text { Chunk content into manageable parts } \\
\text { - Assess students formatively to ensure they make progress } \\
\text { - Create a community among online students } \\
\text { - Build social presence } \\
\text { - Create online environments that are safe and comfortable } \\
\text { - Instill rules for netiquette }\end{array}$ \\
\hline $\begin{array}{l}\text { (6) Assess student } \\
\text { learning }\end{array}$ & $\begin{array}{l}\text { - } \text { Design assessment for courses } \\
\text { - } \text { Provide timely, meaningful, and consistent feedback } \\
\text { - } \text { Evaluate and revise assessments in courses } \\
\text { - } \text { Provide individual and group feedback } \\
\text { - } \text { Use student data to guide the feedback process } \\
\text { - } \quad \text { Provide information to students about their progress } \\
\text { - } \quad \text { Provide feedback in written, audio, and video forms }\end{array}$ \\
\hline
\end{tabular}

\section{Acquiring Competencies for Online Instructors}

In response to the question about what novice online instructors do to acquire strong competencies to be successful in online learning, all participants mentioned some form of professional development, either at one's own institution, within a professional organization, or 
alone. They asserted that faculty members who use technology for their own learning and research, have engaged in online activities and webinars, or have taken a Massively Open Online Course (MOOC), are more likely to become expert online instructors, as are those that possess a studentcentered teaching approach.

Professional development within an institution. Participants shared that the instructor's own institution is the first place to begin acquiring competencies to successfully teach online. They shared the different types of professional development available at their own and other institutions (e.g. in centers of teaching excellence), such as workshops, programs for online teaching, and initiatives about peer teaching. They asserted that it is important for an online instructor to be proactive and take advantage of resources at their own institution.

Several institutions offer faculty workshops or programs for learning to teach online. A fundamental component of such programs is that faculty members learn about online teaching within an LMS and as online learners. One of the participant observed that this was valuable because "experience of being an online learner can help them understand the frustrations that students can experience as well as reflects for them that this environment can really work well for delivering curriculum to students." Other components of such training that participants highlighted are understanding student learning, best practices in online teaching, engagement strategies, and new technologies. They further shared that observing and discussing excellent online courses, conversations with excellent online instructors, or formal reviews of peer online teaching (within and across disciplines) were also innovative strategies used by some higher education institutions.

Professional development with a professional organization. Several professional organizations such as the Online Learning Consortium and Quality Matters offer webinars, workshops, certificates, and other forms of professional development in online teaching. Participants highly recommended participation in professional development to learn about theories that underlie online teaching, the instructional design process, the affordances of learning technologies, and establishing presence in an online course. More importantly, they stated that such an experience provides exposure to "sophisticated online courses," experienced instructors, and an environment to talk to other instructors who are also learning. Instructors can then apply what they learn to their own courses.

Learning on one's own. Participants suggested that those who do not have access to professional development at their own institution can become expert online instructors by learning on their own. One participant stated, "If the institution doesn't have those materials today, find them yourselves. Sign-up for webinars. Look for opportunities to increase your knowledge. When you go to conferences, attend sessions in online learning and teaching."

Participants provided the following suggestions:

- Take the time to get to know and learn to use the learning management system.

- Find resources that can help you become a better online instructor.

- Be proactive in searching for materials.

- Be reflective about online teaching. Review a course to identify what is working.

- Become an expert in data that can provide information on how students are learning.

- Learn to correlate what is being done in an online course to how students are learning.

- Partner with a colleague to review each other's online courses and provide suggestions.

- If there is a strong online course within the institution or department, request to view it.

- "Stick with it." Try new strategies and situations in order to understand what works. 
- Take an online or open online course.

Table 5.

Tasks of Online Instructors

\section{Course Design}

- Structure and organize an online course

- Find and select content

- Make content decisions

- Define course activities

- Chunk content appropriately

- Develop materials and activities

- Design assessments

- Develop syllabi

- Review and revise previous course offerings

\section{Teaching}

- Begin with a welcome activity (e.g., welcome video, discussion forum, student information survey)

- Interact with students

- Facilitate discussions

- Comment on discussions

- Summarize / synthesize online discussions

- Provide direct feedback

- Try to be empathetic

- Be actively visible, present, and engaged

- Use audio or video to communicate with students

\section{Discussion}

As evidenced by this study, we stand to gain a tremendous amount of knowledge from award-winning online instructors and their diverse teaching experiences. Following the template provided by both Bawane (1999) and Alvarez, Guasch and Espaso (2009), we identified the roles, competencies, and tasks of online instructors by interviewing eight award-winning online instructors from across the United States. We provide the following implications for consideration of both future research and practice.

Roles and competencies can vary across researchers in how they are represented (Bawane \& Spector, 2009), but there are notably two common styles. Researchers study the roles and competencies of online instructors to better understand what is required to teach online. Some researchers describe competencies as "actor" roles (Thach \& Murphy, 1995; Goodyear et al., 2001; Williams, 2003; Dennis et al., 2004; Aydin, 2005; Richey et al., 2005; Varvel, 2007), while others view competencies as categories of skillsets or areas of proficiency (Salmon, 2000; Reid, 2002; Klein et al., 2004; Shank, 2004; Richey et al., 2005; Bawane \& Spector, 2009). While the early competency framework by Thach and Murphy (1995) very clearly delineates between roles and competencies, researchers later began to show overlaps when classifying roles and competencies. Bawane and Spector (2009) compiled a comprehensive list of online instructor roles and competencies by seeking out commonalities and eliminating overlaps from existing researchers. Their list no longer delineates between either of the two styles, but rather represents both actor roles and skill categories. In our exploratory study, the summarized list of roles and responsibilities (Table 1) and competencies (Table 2) derived from our interviews with awardwinning instructors show some overlaps, but clearly delineate roles as "actor roles" and competencies as categories of skillsets or areas of proficiency.

Online course facilitation, design, and evaluation are most commonly represented in the current and previous research as a pedagogical role or competency. In the current study, the most important role mentioned by interviewees was that of facilitator. Previous researchers have found that facilitation is a critical role for instructors to implement instructional strategies 
(Bawane \& Spector, 2009) and can vary as an instructor (Dennis et al., 2004; Egan \& Akdere (2005); Thach \& Murphy, 1995; Williams, 2003), process facilitator (Aydin, 2005; Goodyear et al., 2001; Reid, 2002), and content facilitator (Dennis et al., 2004; Goodyear et al., 2001). Our findings show that the facilitator role extends beyond just course delivery, and includes broader pedagogical tasks of welcoming students, helping students manage time and feel comfortable, being responsive to students' needs, being "present" in online activities or forums, communicating/checking in with students regularly, assigning activities and formative activities, providing timely, actionable, and substantive feedback, and fostering student engagement, interest, and interaction. Anderson et al. (2001) suggested that teaching presence can be achieved through "the design, facilitation, and direct instruction of cognitive and social processes for the purpose of realizing personally meaningful and educationally worthwhile learning outcomes" (Anderson et al., 2001, p. 5).

Online instructor roles vary according to the various points in time of an online course. Our findings indicate that online instructors take on several roles at different times of the course where, in some cases, the instructor is a course designer, facilitator, or teacher, while at other times, the instructor is required to be a mentor, "cheerleader," and even a "rule-setter." While most of the studies in the literature list key roles and competencies, Abdous (2011) found that it was unclear how the roles and competencies mapped back to the teaching process and that this created a source of confusion and mismatched expectations for instructors teaching online. Abdous (2011) proposed to map instructor roles and competencies to various stages of the teaching process, suggesting a process-oriented framework describing online teaching as three sequential, nonlinear/iterative phases with specific competencies: (1) before: preparation, planning, and design; (2) during: facilitation, interaction, and feedback; and (3) after: reflection. With this framework, more targeted professional development training can be provided for instructors.

Our study reveals roles, competencies, and tasks that align to each phase of the teaching process. Participants indicate that it is the instructor's role to plan and design courses, to demonstrate various design tasks (Table 3 ) to develop a syllabus, to establish learning objectives, to use backwards design to align course objectives to content and delivery approach, to integrate active learning, to ensure accessibility and ADA-compliance, to chunk content into manageable parts, to select content and develop lessons in a logical sequence, and to develop materials and assessments. This first phase is critical in providing the online course with a structure (Abdous, 2011). One relevant competency that aligns to planning and designing courses is acquiring a strong knowledge of how people learn (Table 2) in synchronous and asynchronous modes to better develop a mix of activities for various learning styles.

Our interviews strongly emphasize the role of facilitator during the actual teaching of the course. In this phase, instructors are expected to perform various teaching tasks (Table 3). Adbous (2011) explains that in this phase, facilitation, interaction, and feedback become the core activities of online teaching. Additionally, instructors need to "share, listen, answer questions, and show enthusiasm, while paying careful attention to students' needs, providing direction, and drawing students toward active engagement and participation in the discussion" (p. 67). Similarly, our participants indicated that instructors need to welcome students, model and initiate discussions, respond with comments and summaries, be actively visible, present, and engaged, and use audio or video to communicate with students. Our participants also discussed the importance of providing timely, actionable, and substantive feedback, through formative assessment strategies of quizzes, discussion posts, online meetings or synchronous sessions, short papers, projects, etc. Bawane and Spector (2009) describe that instructor role of evaluator is necessary to monitor and 
assess performance. Many researchers further describe the role also as an assessor (Aydin, 2005; Goodyear et al., 2001; Dennis et al., 2004; Varvel, 2007).

Our study emphasizes the need for instructors to maintain a strong willingness to learn and grow in their pedagogical and technology skills. This requires seeing oneself as a lifelong learner, allotting time to learn about online teaching and learning, staying abreast of the latest research, theories, and techniques of teaching online, experimenting with technologies, making mistakes and learning from them. Abdous (2011) frames these as continuous learning tasks in the "after" phase of the teaching process, expecting instructors to reflect and note lessons learned.

Online instructor roles vary according to available institutional support and structures. The course designer role and competency commonly appear in the literature on online teaching roles and competencies. In fact, Thach and Murphy (1995) indicate that it is a major role parallel to an instructor and administrator, distinguishing it from supporting instructor roles such as librarian, editor, technician, graphic designer, and support staff. While the literature on instructor roles and competencies suggests that a broad range of skills are needed by faculty members who teach online, those competencies perceived as important to an instructor will vary in practice by institution, particularly dependent on the online education model being implemented (Williams, 2003), academic discipline (Darabi, Sikorski, \& Harvey, 2006), professional development and support available (Bawane \& Spector, 2009a), and delivery modes (Williams, 2003). For example, higher education institutions with small online course development support teams will offer less support for instructors and require faculty members to do more (or almost everything) on their own; this implies that instructors will need to perform more roles and acquire additional competency skills in order to plan, design, develop, facilitate, manage, evaluate, and revise online courses on their own. However, higher education institutions with larger online course development support teams may take over some of those "supporting" roles (Thach \& Murphy, 1995) that faculty members are expected to assume. In effect, development teams consisting of librarians, editors, graphic designers, and instructional designers in such institutions have begun to collaborate with faculty members to assist or redistribute the workload required for online course design, development, and revision. Centers for teaching and learning offer the resources and support required for faculty to be engaged in collaborative course development programs. With such emerging structures in higher education institutions, instructors are expected to largely play the role of subject matter expert (Table 1) and require content expertise (Table 2). As Thach and Murphy (1995) have indicated, instructors will require competency in interpersonal communication, planning skills, collaboration/teamwork skills, as well as knowledge of distance education, and basic technical skills.

Mentoring is critical during the online teaching process. It is in the "during" phase of the teaching process (Abdous, 2011) where instructors are expected to mentor or advise students about their academic and professional development, going beyond just "teaching." Our interviewees viewed themselves as mentors who try "to instill what the profession is about," speaking to students about career goals and pathways. While the adviser/mentor competency or role was not included in earlier competency framework of Thach and Murphy (1995), the mentor role, also represented as advisor or counselor was included in later research (Goodyear et al 2001, Dennis et al 2004, Aydin, 2005; Bawane \& Spector, 2009). Aydin (2005) further describes that online mentors play the role of "academic advisor" in providing pedagogical support to students by guiding students on assignments, answering assignment-related questions, and assessing assignments. In addition, they are expected to solve technical problems or direct them to related support services (Aydin, 2005). 


\section{Limitations}

There are several limitations to this exploratory, qualitative research study. First, the study had a sample size of only eight award-winning online faculty members. The pool of award-winning faculty is clearly limited by the number of award winners in the two professional associations used in the present study. These faculty members were selected from well-established professional associations in online learning spaces, thus adding credibility to our inclusion criteria. Although the sample size is small, the data collected from these individuals are the essence and focus of the research study. Second, in this qualitative interview, the researchers depended on participants' ability to accurately recall and describe details about their award-winning online courses. Some of the faculty had not taught this course in a while due to moving to administrative positions or due to other job responsibilities and this might have affected their ability to recall all the details about their course. However, not all of the interview questions specifically aligned with the faculty members' online course specifically, as some questions were broader and tapped the faculty members' perspectives on the topic of competencies and roles of online instructors. Third, due to time constraints of the participants, we were unable to do a respondent validation of the interviews (i.e., member-checking), which would have potentially strengthened or enhanced the accuracy, credibility, and transferability of our findings.

\section{Future Research}

There remain many unanswered research questions in the realm of online learning. This article has contributed to our understanding of the roles and competencies of online instructors as described by award-winning online faculty members from across the United States. This research has opened new doorways to future research opportunities in the online learning community. Award-winning faculty perspectives about online learning offer a credible data source for researchers to examine on a wide variety of topics. In this study, we chose to focus on the roles and competencies of online instructors. In related research, we are exploring the design, organization, facilitation, and assessment of courses by award-winning faculty. Future research could choose to examine other constructs, such as course delivery systems and modalities, salient design features, facilitation strategies, or even differences among content areas (e.g., arts, sciences, mathematics, etc.) taught online. Award-winning online instructors are a credible and valuable source of information about online learning.

Building and extending on the roles and competencies described in the present study and aligned with current and past research, future research should aim at building a measurement system to validate the roles and competencies identified. By validating the roles and competencies on a wide array of experienced online instructors, we can begin to group, rank, and sort the various items into useful information that can assist with the orientation and ongoing professional development of online instructors. Further, such a measurement system could be used to correlate data to other known behaviors and measures of online teaching and learning to provide convergent and discriminant validity evidence. This type of information is valuable not only to researchers, but to online instructors and administrators of online programs.

\section{Conclusion}

It is our hope that this research adds to the ongoing discussion about the roles and competencies of online instructors. Novel to this research is the credibility of our data sourceaward-winning online instructors. As researchers, instructors, instructional designers, and administrators continue to grapple with the problems and opportunities offered by online learning spaces, we must continue to learn from each other and share experiences that can help shape the $21^{\text {st }}$ century learning environments. 


\section{References}

Abdous, M. (2011). A process-oriented framework for acquiring online teaching competencies. Journal of Computing in Higher Education, 23(1), 60-77.

Allen, I. E., \& Seaman, J. (2017). Digital learning compass: Distance education enrollment report 2017. Babson Survey Research Group, e-Literate, and WCET.

Allen, I. E., and Seaman, J. (2011). Going the distance: Online Education in the United States. Sloan Consortium, Newburyport, MA.

Alvarez, I., Guasch, T., \& Espasa, A. (2009) University teacher roles and competencies in online learning environments: a theoretical analysis of teaching and learning practices, European Journal of Teacher Education, 32(3), 321-336, DOI: 10.1080/02619760802624104

Anderson, T., Rourke, L., Garrison, D., \& Archer, W. (2001). Assessing teaching presence in a computer conferencing context. Journal of Asynchronous Learning Networks, 5(2),1-17.

Aydin, C. (2005). Turkish mentors' perception of roles, competencies and resources for online teaching. Turkish Online Journal of Distance Education, 6(3). Retrieved from http://tojde.anadolu.edu.tr/

Bawane, J. (1999). A study of the discrepancy between the competencies expected and competencies in practice among the primary school teachers. Unpublished doctoral dissertation, University of Mysore, India.

Bawane, J., \& Spector, J. (2009). Prioritization of online instructor roles: Implications for competency-based teacher education programs. Distance Education, 30(3), 383-397. doi:10.1080/01587910903236536

Beck, D., \& Ferdig, R. E. (2008). Evolving roles of online and face-to-face instructors in a lecture/lab hybrid course (Vol. 7). Retrieved from http://eric.ed.gov/?id=ED499577

Bennett, S., \& Lockyer, L. (2004). Becoming an online teacher: Adapting to a changed environment for teaching and learning in higher education. Educational Media International, 41(3), 231248. doi:10.1080/09523980410001680842

Berge, Z. (2009). Changing instructor's roles in virtual worlds. Quarterly Review of Distance Education, 9(4), 407-415.

Bigatel, P. M., Ragan, L. C., Kennan, S., May, J., \& Redmond, B. F. (2012). The identification of competencies for online teaching success. Journal of Asynchronous Learning Networks, 16(1), 59-77.

Coppola, N., Hiltz, S., \& Rotter, N. (2002). Becoming a virtual professor: Pedagogical roles and asynchronous learning networks. Journal of Management Information Systems, 18(4), 169189. Retrieved from http://www.jmis-web.org/toppage/index.html

Darabi, A. A., Sikorski, E. G., \& Harvey, R. B. (2006). Validated competencies for distance teaching. Distance Education, 27(1), 105-122.

Dennis, B., Watland, P., Pirotte, S., \& Verday, N. (2004). Role and competencies of the etutor. In Proceedings of the Networked Learning Conference 2004. Retrieved from http://www.networkedlearningconference.org.uk/past/nlc2004/proceedings/symposia/sympos ium6/denis_et_al.htm

Easton, S. S. (2003). Clarifying the instructor's role in online distance learning. Communication Education, 52(2), 87-105. 
Egan, T. M., \& Akdere, M. (2005). Clarifying Distance Education Roles and Competencies: Exploring Similarities and Differences Between Professional and Student-Practitioner Perspectives. American Journal of Distance Education, 19(2), 87-103.

Farmer, H. M., \& Ramsdale, J. (2016). Teaching competencies for the online environment. Canadian Journal of Learning and Technology, 42(3).

Goodyear, P. (2002). Teaching online. In N. Hativa \& P. Goodyear, eds, Teacher thinking, beliefs and knowledge in higher education, pp. 79-101. Kluwer: Dordrecht.

Goodyear, P., Salmon, G., Spector, J., Steeples, C., \& Tickner, S. (2001). Competences for online teaching: A special report. Educational Technology Research and Development, 49(1), 6572. doi: 10.1007/BF02504508

Harasim, L., Hiltz, S.R., Teles, L. \& Turoff, M. (1997). Learning networks: A field guide to teaching and learning online. Cambridge, MA: MIT Press.

Kerka, S. (1998). Competency-based education and training: Myths and realities. ERIC Digest Retrieved from http://eric.ed.gov/?id=ED415430

Lackey, K. (2011). Faculty development: An analysis of current and effective training strategies for preparing faculty to teach online. Online Journal of Distance Learning Administration, 14(4), 8.

Palloff, R. M., \& Pratt, K. (2001). Lessons from the cyberspace classroom: The realities of online teaching. San Francisco: Jossey-Bass.

Richey, R.C., Fields, D.C., Foxon, M. (2001). Instructional design competencies: The standards, third edition. Syracuse, NY: ERIC Clearinghouse on Information \& Technology.

Salmon, G. (2000). E-moderating: The key to teaching and learning online. London: Taylor \& Francis.

Shank, P. (2004). Competencies for online instructors: Why have instructor competencies for online instructors? Retrieved from http://www.learningpeaks.com/instrcomp.pdf

Smith, T. C. (2005). Fifty-one competencies for online instruction. The Journal of Educators Online, 2(2), 1-18.

Spector, J. M., \& De la Teja, I. (2001). Competencies for online teaching. ERIC Digest.

Stephenson, J. (2001). Teaching and learning online: Pedagogies for new technologies. London: Kogan Page.

Strauss, A. L., \& Corbin, J. (1990). Basics of qualitative research (Vol. 15). Newbury Park, CA: Sage.

Thach, E. C., \& Murphy, K. L. (1995). Competencies for distance education professionals. Educational Technology Research and Development, 43(1), 57-79.

Varvel, V. (2007). Master online teacher competencies. Online Journal of Distance Learning Administration, 10(1). Retrieved from http://www2.westga.edu/ distance/ojdla/

Wiesenberg, F., \& Stacey, E. (2008). Teaching philosophy: Moving from face-to-face to online classrooms. Canadian Journal of University Continuing Education, 34(1), 63-69. Retrieved from http://www.extension.usask.ca/cjuce/

Williams, P. (2003). Roles and competencies for distance education programs in higher education institutions. American Journal of Distance Education, 17(1), 45-57. doi:10.1207/S15389286AJDE1701_4 